\title{
Lobular Capillary Haemangioma of the Oral Cavity in a 11-Year-Old Child - A Case Report
}

\author{
Meghana Vasant Phadnis ${ }^{1}$, Viddyasagar Prabhakar Mopagar ${ }^{2}$, Shridhar Shetty ${ }^{3}$, \\ Vikranth Shetty ${ }^{4}$, Asha Nara ${ }^{5}$, Ashish Raurale ${ }^{6}$
}

\author{
1,2,5 Department of Paediatric and Preventive Dentistry, Rural Dental College, Pravara \\ Institute of Medical Sciences, Loni Bk, Maharashtra, India, ${ }^{3}$ Department of Paediatric and \\ Preventive Dentistry, Yogita Dental College \& Hospital, Khed, Maharashtra, India, \\ ${ }^{4}$ Department of Orthodontics, Tatyasaheb Kore Dental College and Research Centre, New \\ Pargaon, Kolhapur, Maharashtra, India. ${ }^{6}$ Department of Paediatric and Preventive \\ Dentistry, YCM Dental College, Ahmednagar, Maharashtra, India.
}

\section{INTRODUCTION}

Lobular capillary haemangiomas are benign vascular neoplasms that typically affect the skin or mucous membrane. Majority of the cases reporting lobular capillary haemangioma commonly involve the gingiva. There are rare cases presenting involvement of other parts of the oral cavity like buccal mucosa. The management of vascular lesions is more complex in children due to fear of uncontrollable bleeding. The case presented here reports a successful management of lobular capillary haemangioma of the buccal mucosa in an 11 - year - old child.

Vascular lesions are one of the rare disorders affecting the overall quality of life of a child. American Academy of Paediatric Dentistry (AAPD) has presented numerous lesions, masses, or tumour-like conditions of hard and soft tissues within the oral and maxillofacial regions of children and young adults; most of these lesions being mucosal conditions. Oral vascular tumours encompass a wide spectrum of anomalies in children. In spite of the fact that a few cases are congenital, most of them arise during childhood. ${ }^{1}$ The vascular lesions of childhood are classified into two categories: haemangiomas (proliferating or involuting) and vascular malformations. Haemangioma is a term that envelops a heterogeneous gathering of clinical benign vascular lesions that share similar histologic features and presents as a proliferating mass of blood vessels. Haemangiomas are classified on the basis of their histological ${ }^{1}$ appearance as capillary, mixed or cavernous haemangiomas depending on the size of the vascular spaces or a sclerosing variety that tends to undergo fibrosis. Capillary haemangiomas are of two types; lobular capillary haemangioma and non-lobular capillary haemangioma depending on their histological features.

Lobular capillary haemangioma (LCH) is a common reactive angiomatous proliferation of skin and mucous membranes..$^{2,3}$ LCH (Mills et al. 1980 ) represents an essential, underlying lesion of pyogenic granuloma (PG) ${ }^{4,5}$ Based on the available literature and case reports, several clinical and histological differences were seen between PG and LCH, yet there is no clear distinction between the two and still remains a topic of debate.

The peak prevalence of $\mathrm{LCH}$ is in paediatric population and young adults, with a female predilection. Although LCH is one of the most common soft tissue tumours of head and neck accounting for almost $6 \%$ of all cases, there is a striking predilection for lesions on the gingiva. The occurrence of intraoral haemangiomas at sites such as lips, tongue, buccal mucosa, and palate are extremely rare. LCH is a tumour-like growth of the oral cavity or skin that is considered to be non-neoplastic in nature. The purpose of this paper is to report a case of lobular capillary haemangioma in a paediatric patient and describe the successful treatment of this case.
Corresponding Author: Dr. Meghana Phadnis, Department of Paediatrics and Preventive Dentistry, Rural Dental College, Pravara Institute of Medical Sciences, Loni Bk, Maharashtra, India. E-mail: meghs.p4@gmail.com

DOI: $10.14260 /$ jemds/2021/438

How to Cite This Article:

Phadnis MV, Mopagar VP, Shetty S, et al. Lobular capillary heamangioma of the oral cavity in a 11 - year - old child - a case report. J Evolution Med Dent Sci 2021;10(28):2132-2134, $10.14260 / \mathrm{jemds} / 2021 / 438$

Submission 10-02-2021,

Peer Review 11-05-2021,

Acceptance 19-05-2021,

Published 12-07-2021.

Copyright (C) 2021 Meghana Vasant Phadnis et al. This is an open access article distributed under Creative Commons Attribution License [Attribution 4.0 International (CC BY 4.0)] 


\section{PRESENTATION OF CASE}

A 11 - year - old boy reported to the Department of Paediatric Dentistry with the complaint of swelling in right cheek region inside the oral cavity. The child noticed the presence of the swelling about 15 days back and was unsure whether it was present before that period or not. The child reported episodes of bleeding with minor injuries while eating which stopped after some time. The swelling was painless but caused constant interference during mastication.

On clinical examination a solitary swelling measuring 1.5 $\mathrm{cm} \mathrm{X} 1 \mathrm{~cm}$ was noticed on the right buccal region (Figure 1). The child had poor oral hygiene. The swelling was sessile in nature with a reasonably broad base and was slightly mobile on pressure. The surface of the swelling was rough in nature with areas of bleeding. (Figure 2) On palpation the swelling was tender and the tissue over the swelling was removable suggesting recent infection or constant trauma leading to tissue sloughing over the surface.

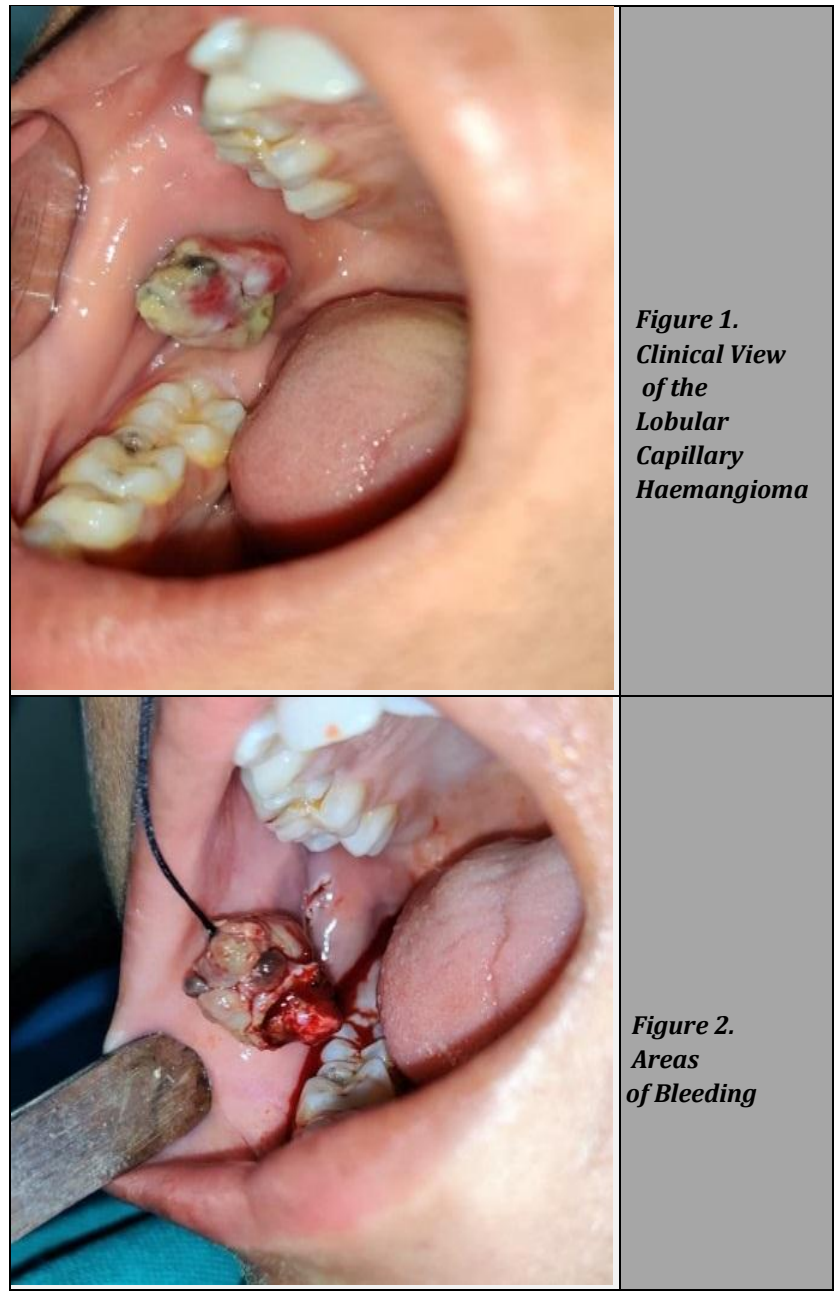

Considering the history and clinical picture of the lesion a provisional diagnosis of pyogenic granuloma was made. Differential diagnosis considered irritational fibroma, haemangioma etc. but the duration of history as only 15 days put the diagnosis at doubt. The patient was advised for total blood picture to rule out any vascular abnormalities and potential risks. The biochemical and other values of blood were in normal range.
Excisional biopsy of the lesion with part of peripheral normal tissue from the buccal area was carried out (Figure 3). The lesion was sent for histopathological examination for definitive diagnosis.

Histopathologically, numerous endothelial cell proliferation in lobules separated by fibrous septa accompanied by dilated capillaries of varying sizes were noticed. (Figure 4) After verification in all the fields the lesion was diagnosed as "Lobular Capillary Haemangioma".

The patient was advised good oral hygiene practices and follow up after one week to monitor healing. The area of incision was healed uneventfully and no clinical problems were reported after one week.

However, the patient was advised strict follow up every three months to evaluate and act if any recurrence was noticed. After six months no signs of recurrence were noticed. (Figure 5)

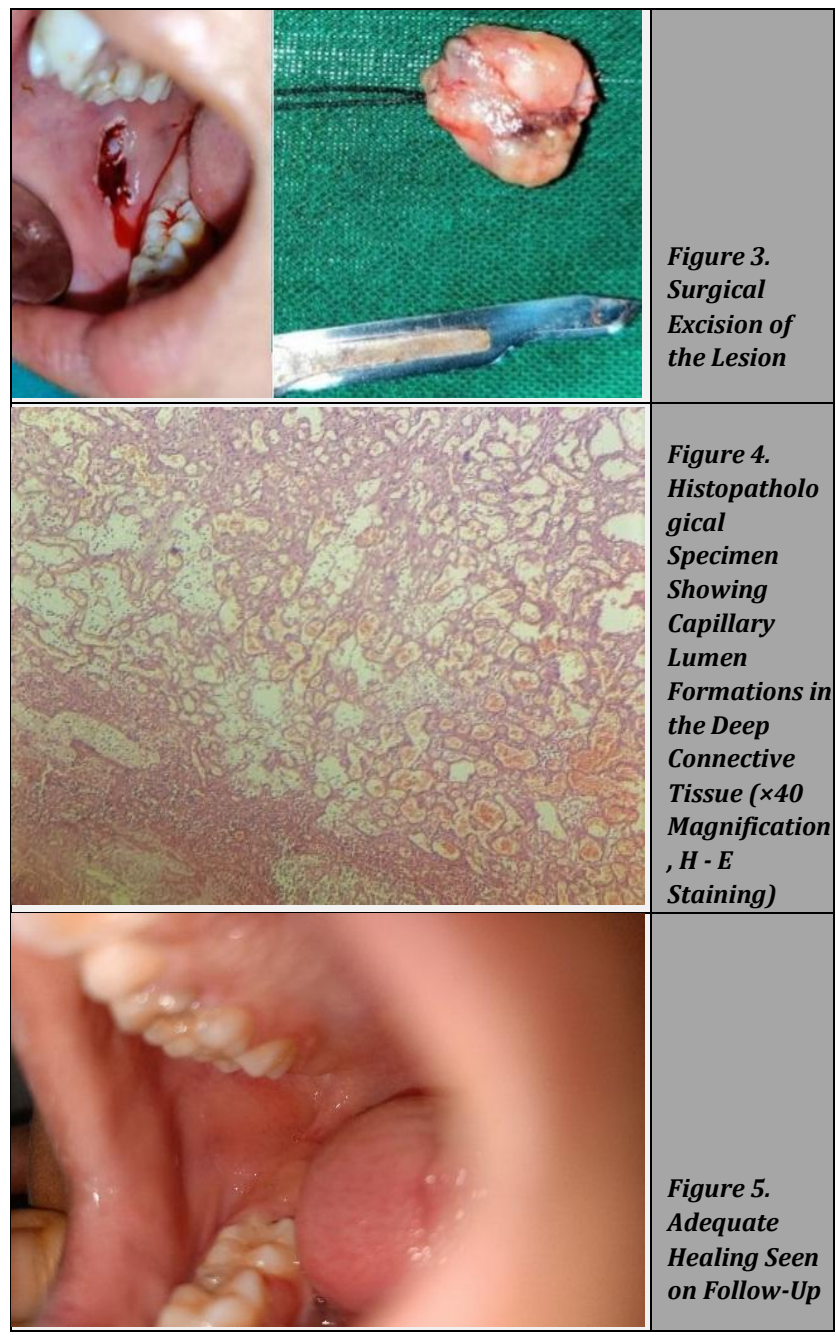

\section{DISCUSSION}

Any type of alterations from the normal physiologic structures in the orofacial area causes severe psychological stress on children as well as parents. Although most of the swellings are not harmful in children, few unattended lesions may lead to serious complications. The spread of such lesions is faster in children when compared to adults and hence any type of growth must be attended immediately and with caution. 
Accurate nomenclature and diagnosis are necessary for appropriate patient management and a successful treatment outcome. In 2014; ISSVA classification system identified lobular capillary haemangiomas as benign vascular tumours.

Lobular capillary haemangiomas mostly occur in the head and neck region including the oral cavity and distal extremities. Oral lesions commonly target the gingiva, particularly the anterior labial maxillary gingiva followed by mandibular and facial gingiva.

Other than gingiva, regions involved are lips, tongue, buccal mucosa, palate, cheek, mucobuccal fold, and frenum. In the paediatric age group, this tumour typically occurs in early childhood and rarely in adolescents, and has a predilection for males. ${ }^{6}$

Aetiology behind lobular capillary haemangioma is unknown, however, trauma such as biting, fractured tooth, poor restorations, chronic local irritation, hormonal factors such as pregnancy or oral contraceptives, poor oral hygiene, and medications play a role in the development of these lesions. The present case showing occurrence of lobular capillary haemangioma with its primary location on the buccal mucosa is extremely rare. The patient had spontaneous bleeding and pain only when subjected to masticatory forces.

Capillary haemangioma clinically would present features such as asymmetry of the face, mobility of teeth, spontaneous bleeding, pain, blanching of tissue, pulsation, expansion of bone, paraesthesia, early exfoliation of primary teeth, delayed eruption, root resorption, and missing teeth.6,7,8 Except spontaneous bleeding other features mentioned were not obvious in the presented case. The child had pain due to secondary infection over and above the trauma caused by mastication. At times these kinds of lesions may be confused with the vascular - appearing lesions of the face or oral cavity, representing the Sturge - Weber syndrome. . $^{9,10}$

Treatment often consists of conservative excision, with or without preprocedural embolization to decrease the risk of bleeding; removal of the etiologic factor, such as trauma and chronic local irritation, and appropriate dental hygiene also aid in disease control. Prognosis is excellent with complete excision of the tumour and is the most acceptable treatment of choice. 8,11 Complications related to surgical excision include failure to control bleeding and in the setting of incomplete excision, failure to remove the inciting factor, and or reinjury to the region, recurrence of oral lesions may occur at a rate of approximately $15 \% .10$ other treatment options used in the management of haemangiomas include oral administration of corticosteroids, interferon $\mathrm{a}-2 \mathrm{~b}$, intralesional injection of fibrosing agents, radiation, electrocoagulation, cryosurgery, laser therapy, embolization, and surgical excision. In the case presented here, considering the age of the patient and the capacity of healing, treatment of LCH was done by complete surgical excision of the lesion without any necessity of the other available treatment modalities. There was proper control of bleeding and on regular follow-ups no recurrence was reported.

\section{CONCLUSIONS}

In summary, there is little evidence of cases reporting with lobular capillary haemangioma involving the buccal mucosa in paediatric patients. Early detection of the pathology and biopsy is necessary to determine the clinical behaviour of the tumour so as to render appropriate treatment.

Financial or other competing interests: None.

Disclosure forms provided by the authors are available with the full text of this article at jemds.com.

\section{REFERENCES}

[1] Enzinger FM, Weiss SW. Soft tissue tumors. Vol. 11. The American Journal of Dermatopathology 1989: p. 593.

[2] Mills SE, Cooper PH, Fechner RE. Lobular capillary haemangioma: the underlying lesion of pyogenic granuloma. A study of 73 cases from the oral and nasal mucous membranes. Am J Surg Pathol 1980;4(5):470-9.

[3] Harris MN, Desai R, Chuang TY, et al. Lobular capillary haemangiomas: an epidemiologic report, with emphasis on cutaneous lesions. J Am Acad Dermatol 2000;42(6):1012-6.

[4] Patrice SJ, Wiss K, Mulliken JB. Pyogenic granuloma (lobular capillary haemangioma): a clinicopathologic study of 178 cases. Pediatr Dermatol 1991;8(4):267-76.

[5] Trobs RB, Mader E, Friedrich T, et al. Oral tumors and tumor-like lesions in infants and children. Pediatr Surg Int 2003;19(9-10):639-45.

[6] Kamal R, Dahiya P, Puri A. Oral pyogenic granuloma: various concepts of etiopathogenesis. J Oral Maxillofac Pathol 2012;16(1):79-82.

[7] Açikgöz A, Sakallioglu U, Ozdamar S, et al. Rare benign tumours of oral cavity--capillary haemangioma of palatal mucosa: a case report. Int J Paediatr Dent 2000;10(2):161-5.

[8] Greene LA, Freedman PD, Friedman JM, et al. Capillary haemangioma of the maxilla. A report of two cases in which angiography and embolization were used. Oral Surg Oral Med Oral Pathol 1990;70(3):268-73.

[9] Mopagar V, Choudhari S, Subbaraya D, et al. Sturge-Weber syndrome with pyogenic granuloma. Contemp Clin Dent 2013;4(3):360-2.

[10] Bhansali RS, Yeltiwar RK, Agrawal AA. Periodontal management of gingival enlargement associated with Sturge-Weber syndrome. J Periodontol 2008;79(3):54955.

[11] Childers ELB, Furlong MA, Fanburg-Smith JC. Haemangioma of the salivary gland: a study of ten cases of a rarely biopsied/excised lesion. Ann Diagn Pathol 2002;6(6):339-44. 